\title{
FORMULATION OF IMMEDIATE RELEASE (IR) ATORVASTATIN CALCIUM PELLETS AND SUSTAINED RELEASE (SR) GLIBENCLAMIDE FOR FIXED-DOSE COMBINATION DOSAGE FORM
}

\author{
KOWSHIK K, VISHAL GUPTA N, GOWDA DV*, PRAVEEN SIVADASU
}

Department of Pharmaceutics, JSS College of Pharmacy, Sri Shivarathreeshwara Nagara, Mysuru, JSS Academy of Higher Education and Research, JSS Medical Institutions Campus, Sri Shivarathreeshwara Nagara, Mysuru, Karnataka, India. Email: dvgowda@jssuni.edu.in

Received: 10 April 2018, Revised and Accepted: 23 July 2018

\section{ABSTRACT}

Objective: The objective of the present research was to develop fixed-dose combinations for the treatment of dyslipidemia, associated with type-II diabetes mellitus for improvement of glucose tolerance.

Methods: Multiple unit pellet systems (MUPSs) consisting immediate release atorvastatin calcium pellets and sustained release glibenclamide were formulated by spheronization technique. The characterization of formulated pellets was done by Fourier transform infrared (FT-IR) and differential scanning calorimetry (DSC) studies, and formulated pellets were evaluated for solubility, viscosity, pH, and in vitro studies.

Results: From FT-IR and DSC studies, it was confirmed that no chemical interaction existed between the drug and the natural polymers used. Solubility of glibenclamide was found to be 4.38 and 18.24 and atorvastatin calcium was found to be $6.84,214.67$, and $287.43 \mathrm{~g} / \mathrm{L}$. The viscosity of $1 \% \mathrm{w} / \mathrm{v}$ of locust bean gum, guar gum, and ghatti gum was found to be $169 \mathrm{cP}, 124 \mathrm{cP}$, and $31 \mathrm{cP}$ in distilled water. The pH of locust bean gum, guar gum, and gum ghatti solutions was found to be $5.6 \pm 0.49,5.2 \pm 0.27$, and $4.7 \pm 0.51$. The in vitro studies suggested that glibenclamide pellets had shown a sustained release till $12 \mathrm{~h}$, while atorvastatin calcium had shown immediate release of drug due to rapid disintegration of pellets.

Conclusion: Thus, MUPS can be considered as an alternative approach to treat diabetes induced dyslipidemia.

Keywords: Multiple unit pellet system, Glibenclamide, Atorvastatin calcium, Sustained release, Immediate release.

(C) 2018 The Authors. Published by Innovare Academic Sciences Pvt Ltd. This is an open access article under the CC BY license (http://creativecommons. org/licenses/by/4. 0/) DOI: http://dx.doi.org/10.22159/ajpcr.2018.v11i12.26629

\section{INTRODUCTION}

Diabetes mellitus is a heterogeneous group of disease characterized by elevation of glucose in the blood because of the impaired insulin secretions in body. Deficiency of insulin leads to chronic hyperglycemia with disturbances of carbohydrate, fat, and protein metabolism [1,2]. As the disease progresses, various tissues or vascular damage leads to many diabetic complications related to retinopathy, neuropathy, nephropathy, cardiovascular, and ulceration, thus diabetes covers a wide range of heterogeneous diseases. It is the most common endocrine disorder and estimated that more than 200 million people were suffering from diabetes [3]. Diabetes can be classified into two types, i.e., Type-I (insulin-dependent diabetes) and Type-II (non-insulindependent diabetes). Patients suffering from Type-II diabetes will not respond effectively to insulin which can be termed as insulin resistance. When the blood glucose or sugar level is high, it can be termed as hyperglycemia, whereas when the blood glucose levels are lower than normal levels, it can be termed as hypoglycemia [4].

In recent times, among various drug delivery systems to treat diabetes induced dyslipidemia, multiple unit pellet systems (MUPSs) have grabbed attention of pharmaceutical industries, as they deliver both immediate and modified release drugs from as single system. The pellets that are present in this multiple unit can be coated or uncoated. When compared with other delivery techniques, these multiple unit pellet delivery systems possess advantages such as reduced toxicity, local irritation and dose dumping, and plasma concentration fluctuations, and it is able to administer high potency drugs [5].

Glyburide [6] is another name for glibenclamide, which comes under the class know as sulfonylureas; further, it is classified as either the second generation or the third generation of sulfonylureas. It is familiarly related as sulfonamide antibiotics, pharmaceutical preparation of glibenclamide is used only for Type-II diabetes and not for Type-I diabetes, because of insufficient production of insulin from pancreas. Glibenclamide acts by binding and inhibiting potassium channel $\left(\mathrm{K}_{\text {ATP }}\right)$ and sulfonylurea receptors in pancreatic beta-cell [7].

Atorvastatin comes under the family of statins; initially, it behaves as lipid-lowering agent and inhibits tasks associated with cardiovascular diseases. Atorvastatin plays a major role by inhibiting 3-hydroxy-3methylglutaryl-coenzyme A (HMG-CoA) reductase, an enzyme which is present in the liver tissue plays a key role in the production of cholesterol in the human body. The reduction of HMG-CoA to mevalonate is also catalyzed by HMG-CoA reductase [8].

Here, in the current research work, a basic pellet formulation consisting a drug and microcrystalline cellulose (MCC) was formulated by employing spheronization technique, to modify the drug release from various excipients which are taken in various proportions and combinations. The main objective of this formulation is to improve the glucose tolerance in Type-II diabetes.

\section{MATERIALS AND METHODS}

Materials

Glibenclamide was purchased from Sanket Pharmaceuticals Pvt., Ltd., Mumbai, and atorvastatin calcium API was purchased from Afton Pharma, Rajkot, Gujarat. All the other chemicals used in the study are of analytical grade.

\section{Methods}

Preparation of drug-loaded sustained release glibenclamide pellets A uniform dry powder mixture (batch size $100 \mathrm{~g}$ ) containing glibenclamide, MCC (Avicel PH 101), locust bean gum, and gum ghatti/ guar gum is taken in polyethylene bag in different concentrations as shown in Table 1 . The above mixture was then granulated using 
water and isopropyl alcohol in 5:2 ratio as granulation fluid. Then, it is extruded, and the extrudates were then immediately spheronized to get the yield. The pellets were dried in hot air oven at $40^{\circ} \mathrm{C}$ for $10-12 \mathrm{~h}$ and stored in screw-capped, high-density polyethylene bottles [9].

Preparation of drug-loaded immediate release atorvastatin calcium pellets

Similar to above glibenclamide pellets formulation, uniform dry powder mixture (batch size $100 \mathrm{~g}$ ) containing atorvastatin calcium and excipients such as MCC (Avicel PH 101), sodium starch glycolate/croscarmellose sodium, sodium lauryl sulfate (SLS), and sodium bicarbonate was taken in polyethylene bag as shown in Table 2. The mixture was then granulated using $1 \% \mathrm{w} / \mathrm{w}$ locust bean gum/PVP K-30 in water as granulation fluid. Then, the wet granulation mixture was extruded, and the extrudates were then immediately spheronized to yield the spherical pellets. The pellets were dried in hot air oven at $40^{\circ} \mathrm{C}$ for $10-12 \mathrm{~h}$. After drying, pellets were then filled and stored in screw-capped, high-density polyethylene bottles [9].

\section{Preformulation studies}

The following preformulation studies were performed for glibenclamide and atorvastatin calcium pure drugs.

Fourier transform infrared (FT-IR) studies of glibenclamide and atorvastatin calcium

To determine compatibility of the drug and polymer, Fourier transforminfrared (FT-IR) spectroscopy was done. Results were recorded using FT-IR (8400S, Shimadzu Corporation, Japan). API dispersed with $\mathrm{KBr}$ in mortar, the material is triturated into fine powder with the help of compression gauge the powder has been compressed in a holder, and pressure of 5 ton is applied for $5 \mathrm{~min}$. The pellet was placed in the light path and results were recorded [10].

\section{Differential scanning calorimetry (DSC)}

DSC studies were carried out on Shimadzu thermal analyzer. A few milligrams of sample were hermetically sealed into aluminum pans and heated under nitrogen atmosphere with the heating rate of $10^{\circ} \mathrm{C} / \mathrm{min}[11]$.

\section{Solubility}

Solubility studies of glibenclamide and atorvastatin calcium were carried out using distilled water. Glibenclamide and atorvastatin calcium were taken in vials containing distilled water. The vials were subjected to stirring for $24 \mathrm{~h}$ on a magnetic stirrer, and the obtained solution was filtered and the filtrate was estimated spectrophotometrically at wavelengths of $242 \mathrm{~nm}$ for glibenclamide and $246 \mathrm{~nm}$ for atorvastatin calcium, respectively [12]

\section{pH of gums}

The accurate measurement of $\mathrm{pH}$ was done using probe $\mathrm{pH}$ meter. Measurement was done by submerging the probe in the liquid until a reading is registered by the meter.

\section{Micromeritic properties}

Micromeritic properties for both glibenclamide and atorvastatin calcium such as angle of repose, Carr's index, as well as tapped density were determined. The tapped density was determined using a tapped density tester in which the glass cylinder was tapped 100 times. To measure the tapped density, the process was continued until a constant value was attained. Angle of repose was the most widely used technique for measuring the flowability [by determining the shape of the powder heap]. The formula used to measure the flowability [13].

\section{Scanning electron microscopic (SEM) studies}

SEM was employed to investigate the surface morphology of the pellets which were prepared, before coating around the pellets during analysis. SEM was performed at $5 \mathrm{kV}$ having different magnifications using Hitachi Noran System 7 manufactured by Thermo Fisher Scientific [14].

\section{Evaluation of prepared pellets}

Friability and pellet yield

Friability of pellets was determined by Roche friabilator. $10 \mathrm{~g}$ of pellets were subjected to testing at $25 \mathrm{rpm}$ for $4 \mathrm{~min}$. Samples were sieved and the pellets retained on the sieve were weighed, and percent friability

Table 1: Formulation chart of sustained release glibenclamide pellets

\begin{tabular}{|c|c|c|c|c|c|c|}
\hline \multicolumn{6}{|c|}{ Ingredient concentration $(\% \mathrm{w} / \mathrm{w})$} & \multirow{2}{*}{$\begin{array}{l}\text { Wetting agent volume } \\
\text { (Water: IPA) }(5: 2)(\mathrm{mL} / \mathrm{g})\end{array}$} \\
\hline Formulation Code & Glibenclamide & MCC & Locust bean gum & Gum ghatti & Guar gum & \\
\hline BD-1 & 2.5 & 96.5 & 1 & - & - & 0.80 \\
\hline BD-3 & 2.5 & 94.5 & 3 & - & - & 0.77 \\
\hline $\mathrm{BD}-4$ & 2.5 & 95.0 & 2 & 0.5 & - & 0.70 \\
\hline BD-5 & 2.5 & 94.5 & 2 & 1 & - & 0.77 \\
\hline BD-6 & 2.5 & 94.0 & 2 & 1.5 & - & 0.84 \\
\hline BD-7 & 2.5 & 93.5 & 2 & 2 & - & 0.84 \\
\hline BD-8 & 2.5 & 93.0 & 2 & 2.5 & - & 0.80 \\
\hline BD-9 & 2.5 & 95.0 & 2 & - & 0.5 & 0.74 \\
\hline BD-10 & 2.5 & 94.5 & 2 & - & 1 & 0.74 \\
\hline
\end{tabular}

Table 2: Formulation chart of immediate release atorvastatin calcium pellets

\begin{tabular}{|c|c|c|c|c|c|c|}
\hline \multicolumn{7}{|c|}{ Ingredient concentration $(\% \mathrm{w} / \mathrm{w})$} \\
\hline Formulation & Atorvastatin calcium & MCC & SSG & CCS & Sodium bicarbonate & SLS \\
\hline FR-1 & 4 & 92 & 1 & - & 2 & 1 \\
\hline FR-2 & 4 & 91 & 2 & - & 2 & 1 \\
\hline FR-3 & 4 & 90 & 3 & - & 2 & 1 \\
\hline FR-4 & 4 & 89 & 4 & - & 2 & 1 \\
\hline FR-5 & 4 & 88 & 5 & - & 2 & 1 \\
\hline FR-6 & 4 & 87 & 6 & - & 2 & 1 \\
\hline FR-7 & 4 & 86 & 7 & - & 2 & 1 \\
\hline FR-8 & 4 & 92 & - & 1 & 2 & 1 \\
\hline FR-9 & 4 & 91 & - & 2 & 2 & 1 \\
\hline FR-10 & 4 & 90 & - & 3 & 2 & 1 \\
\hline
\end{tabular}


was calculated from the difference in the weight of the pellets before and after friability.

\section{Drug loading and encapsulation efficiency}

To the freshly prepared $100 \mathrm{ml}$ phosphate buffer of $\mathrm{pH} 6.8$ with $0.5 \%$ $\mathrm{w} / \mathrm{v}$ SLS, a specific amount of crushed pellets were suspended with constant agitation at room temperature for $24 \mathrm{~h}$. The final solution was filtered via Whatman filter paper, and drug content was determined separately for each pellet formulation by spectrophotometric method at the specific wavelengths.

\section{Pellets disintegration time}

Special transparent tubes having the diameter of $10-\mathrm{mm}$ and $15-\mathrm{mm}$ length were employed in pellet disintegration tester. The sieves of 710$\mathrm{mm}$ mesh size were at bottom and as well as top of the tubes. $100 \mathrm{mg}$ of pellets is filled in the tubes and they were placed in the standard tablet disintegration tester. The disintegration time of six dried samples at $37^{\circ} \mathrm{C}$ was determined at a speed of 30 dips. Disintegration test was carried out 3 times for each formulation, and results were expressed [14].

\section{In vitro dissolution studies}

Electrolab USP dissolution testing apparatus I (basket type) was used to evaluate the rate of drug release from formulated pellets. A weighed quantity equivalent to $100 \mathrm{mg}$ of pellets was taken in $500 \mathrm{~mL}$ of $7.4 \mathrm{pH}$ phosphate buffer. The test was carried out for $12 \mathrm{~h}$ at $37 \pm 1^{\circ} \mathrm{C}$ and $100 \mathrm{rpm} .2 \mathrm{~mL}$ of sample was withdrawn at preset time intervals and replaced with equal volume of dissolution medium. Withdrawn sample was filtered and analyzed spectrophotometrically at wavelength of $242 \mathrm{~nm}$ and $246 \mathrm{~nm}$ [14].

\section{RESULTS AND DISCUSSION}

\section{Solubility}

Solubility of glibenclamide was found to be $4.38,18.24$, and $24.09 \mathrm{~g} / \mathrm{L}$ in $\mathrm{pH} 1.2,6.8$, and 7.2. Similarly, the solubility of atorvastatin calcium was found to be $6.84,214.67$, and $287.43 \mathrm{~g} / \mathrm{L}$ in $\mathrm{pH} 1.2,6.8$, and 7.2 phosphate buffers, respectively. From the results, it can be inferred that both glibenclamide and atorvastatin calcium were more soluble in alkaline $\mathrm{pH}$, i.e., $>7$.

\section{pH of gums}

The locust bean gum is a non-ionic neutral polysaccharide and it reduces syneresis at a $\mathrm{pH}$ range of $5.6 \pm 0.49$, guar gum had shown results to treat diabetes, and $\mathrm{pH}$ of guar gum obtained was $5.2 \pm 0.27$. Ghatti gum having a pH range of $4.7 \pm 0.51$ was favorable for formulation of pellets.

\section{Characterization of sustained release glibenclamide pellets FT-IR studies of glibenclamide}

The position of peak in FT-IR spectra of pure glibenclamide is compared with those in FT-IR spectra of glibenclamide with excipients as shown in Fig. 1. FT-IR spectral analysis indicates that the characteristic absorption peaks present in the IR spectra of glibenclamide drug were also found in the physical mixtures of the polymers used (locust bean

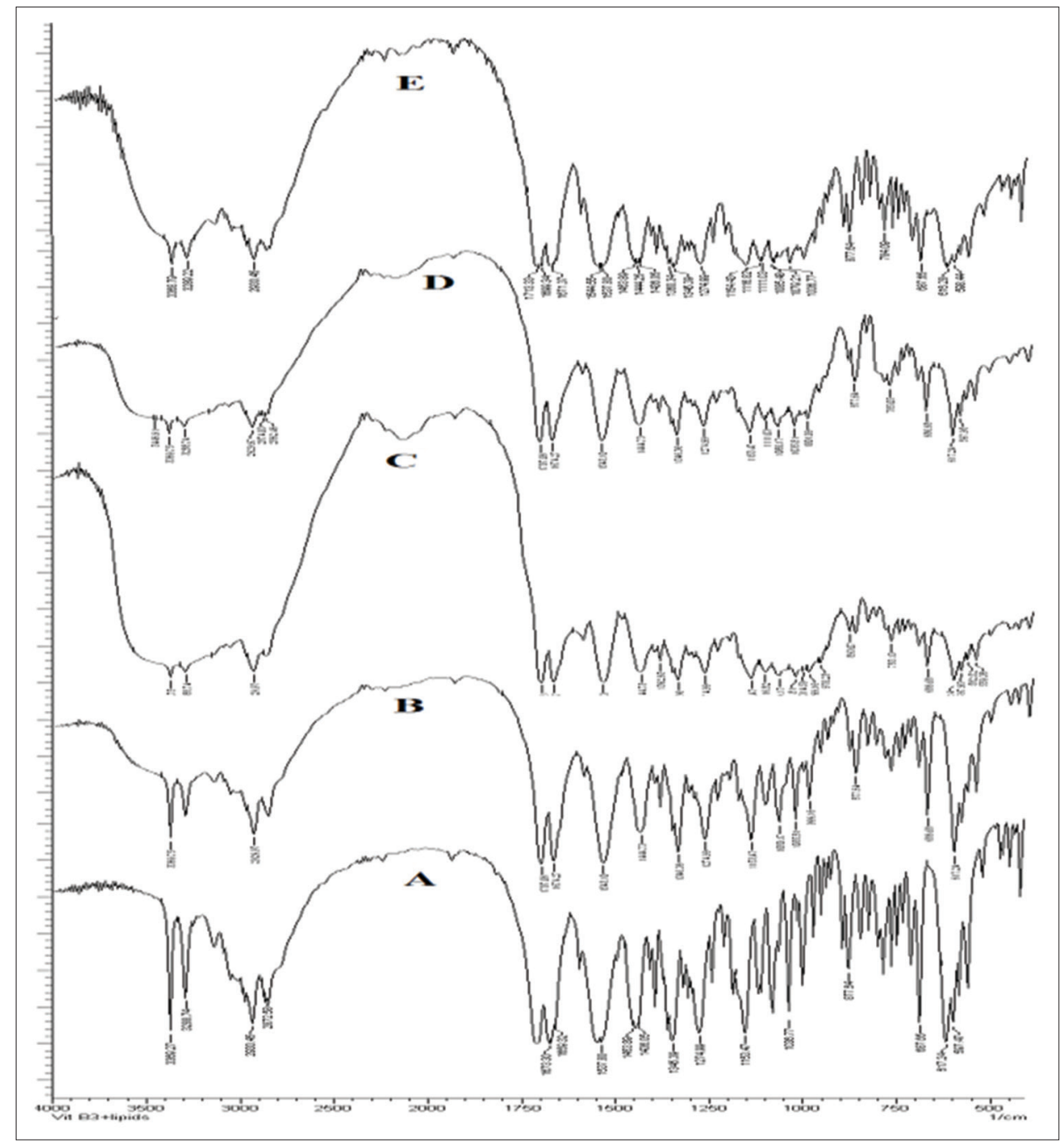

Fig. 1: Fourier transform infrared spectra of (a) glibenclamide pure drug, (b) glibenclamide + locust bean gum, (c) glibenclamide + gum ghatti; (d) glibenclamide + guar gum; (e) glibenclamide + MCC 
gum/gum ghatti/guar gum/MCC) without any appreciable change in the position, attributing to the compatibility of drug-polymer. Hence, it can be inferred that drug can be used with the selected polymer without causing any instability in the formulation.

\section{FT-IR studies of atorvastatin calcium}

The position of peak in FT-IR spectra of pure atorvastatin calcium is compared with those in FT-IR spectra of atorvastatin calcium with excipients as shown in Fig. 2. FT-IR spectral analysis indicates that the absorption peaks present in the IR spectra of atorvastatin calcium were also found in the physical mixtures of the excipients used (MCC/ locust bean gum/sodium starch glycolate/croscarmellose sodium/ SLS/sodium bicarbonate/PVP K-30) without any appreciable change in the position, attributing to the compatibility of drug-polymer. From the obtained results, it can be inferred that drug can be used with the selected polymer without causing instability in the formulation.

\section{DSC studies of glibenclamide}

From Fig. 3, it was evident that glibenclamide showing a sharp endothermic peak at its melting point, i.e., at $213.83^{\circ} \mathrm{C}$, indicating its crystalline nature of the drug. On the other hand, the DSC thermographs of formulation BD2 , BD-8, and BD-13 showed identical peaks, to that of pure drug indicating the absence of chemical interaction between the drug and polymers.

\section{DSC studies of atorvastatin calcium pellets}

The thermal analysis of pure atorvastatin calcium API showed a sharp endothermic peak at its melting point, i.e., at $156.87^{\circ} \mathrm{C}$, demonstrating its crystalline nature. On the other hand identical, but broad peaks were found on DSC analysis of formulations FR-7, FR-14, and FR-15, indicating no interaction of atorvastatin calcium with its polymers and excipients. DSC thermograms of atorvastatin calcium API, formulation FR-7, FR-14, and FR-15 are presented in below Fig. 4.

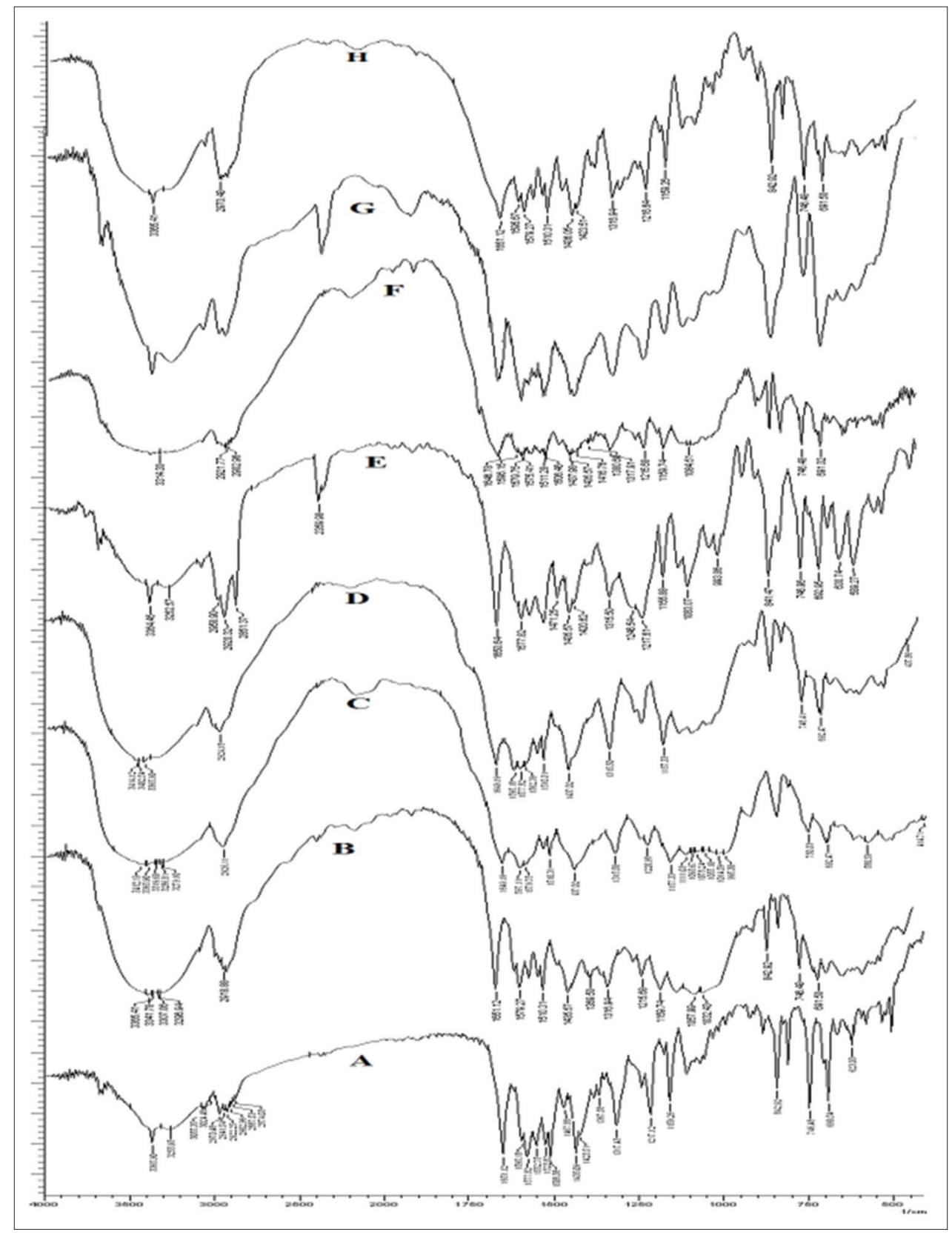

Fig. 2: Fourier transform infrared spectra of (a) atorvastatin calcium pure drug, (b) atorvastatin calcium + microcrystalline cellulose;

(c) atorvastatin calcium + sodium starch glycolate; (d) atorvastatin calcium + croscarmellose sodium; (e) atorvastatin calcium + sodium lauryl sulfate; (f) atorvastatin calcium + locust bean gum; (g) atorvastatin calcium + sodium bicarbonate; (h) atorvastatin calcium + PVP K-30 


\section{Micromeritic properties of glibenclamide}

The micromeritic properties of different batches of sustained release glibenclamide pellets are summarized in Table 3. The properties such as average size ( $\mathrm{mm}$ ), angle of repose, Carr's index, and tapped density explain that no respective change differences among all batches. Angle of repose having a range of $23.20 \pm 1.35-27.35 \pm 1.58^{\circ}$ which indicates good flow properties of pellets. The bulk density results of different batches of sustained release glibenclamide pellets indicated closely packed and settled nature because of narrow particle size distribution.

\section{Micromeritic properties of atorvastatin calcium}

The micromeritic properties of different batches of immediate release atorvastatin calcium pellets are summarized in below Table 4 . The properties such as average size $(\mathrm{mm})$, angle of repose, Carr's index, and tapped density did not show any significant differences among

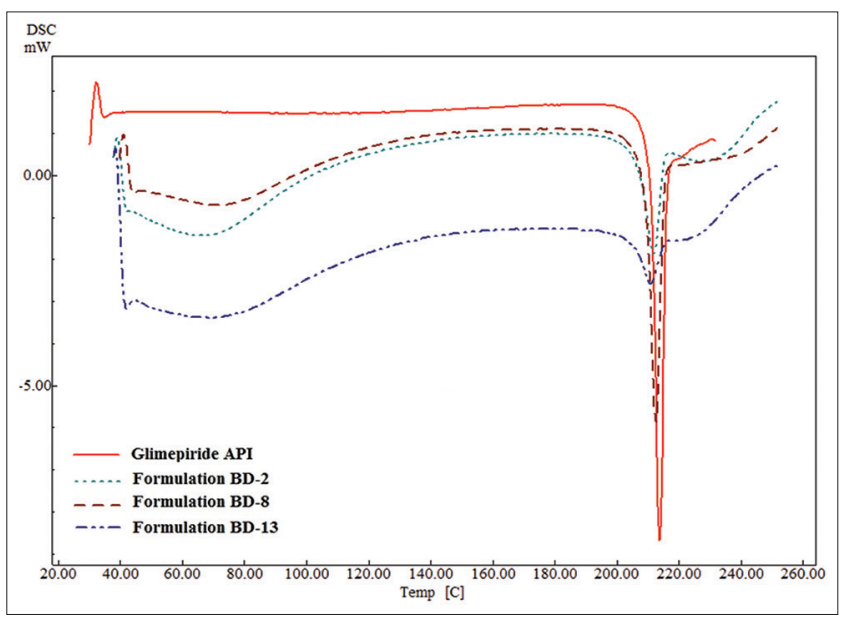

Fig. 3: Differential scanning calorimetry thermogram of glibenclamide API, formulation BD-2, BD-8, and BD-13 the batches. Angle of repose was found to be within the range of $24.19 \pm 1.33-27.21 \pm 1.69^{\circ}$ indicating good flow properties of pellets.

\section{SEM studies of glibenclamide pellets}

From the SEM photographs (Fig. 5), it was observed that the sustained release glibenclamide pellets formulated using locust bean gum and gum ghatti/guar gum polymers exhibited spherical shape. The pellets consisting of locust bean gum alone and locust bean gum with gum ghatti polymer were of smoother surface, while pellets prepared using guar gum along with locust bean gum showed chapped surface.

\section{SEM studies of atorvastatin calcium pellets}

From the SEM photographs (Fig. 6), it was observed that the immediate release atorvastatin calcium pellets formulated using $1 \% \mathrm{w} / \mathrm{w}$ locust bean gum as binder and sodium starch glycolate/croscarmellose sodium exhibited spherical shape. The pellets consisting of locust bean gum and sodium starch glycolate were of smoother surface, while pellets prepared using locust bean gum and croscarmellose sodium showed chapped surface.

Evaluation of glibenclamide pellets and atorvastatin calcium pellets Friability and pellet yield of glibenclamide

The results of friability test and pellet yield of the sustained release glibenclamide pellet formulations were summarized. The friability of the sustained release glibenclamide pellet formulations was found to be in the range of $0.32 \pm 0.08-0.53 \pm 0.07 \%$ results were in acceptable limits. The pellet yield was in the range of $76.9 \pm 2.31-83.3 \pm 3.16 \%$ in successive unit operations when $100 \mathrm{~g}$ of bulk material is being used.

Friability and pellet yield of atorvastatin calcium

The results of friability test and pellet yield of the immediate release atorvastatin calcium pellet formulations were summarized. The friability of the immediate release atorvastatin calcium pellet formulations was found to be in the range of $0.44 \pm 0.02-0.54 \pm 0.05 \%$ results were in acceptable limits. The pellet yield was in the range of

Table 3: Characteristics of sustained release glibenclamide pellets formulation

\begin{tabular}{|c|c|c|c|c|c|}
\hline $\begin{array}{l}\text { Formulation } \\
\text { code }\end{array}$ & Average size (mm)* & Angle of repose $\mathrm{e}^{* *} \boldsymbol{\theta}^{\circ}$ & $\begin{array}{l}\text { Granule density } \\
\left(\mathrm{g} / \mathrm{cm}^{3}\right)^{* *}\end{array}$ & $\begin{array}{l}\text { Tapped density } \\
\left(\mathrm{g} / \mathrm{cm}^{3}\right)^{* *}\end{array}$ & $\begin{array}{l}\text { Carr's index } \\
(\%)^{* *}\end{array}$ \\
\hline BD-1 & $1135 \pm 51$ & $25.14 \pm 1.24$ & $1.05 \pm 0.03$ & $0.84 \pm 0.04$ & $9.12 \pm 0.32$ \\
\hline BD-2 & $1189 \pm 25$ & $26.42 \pm 1.18$ & $1.03 \pm 0.04$ & $0.86 \pm 0.07$ & $8.79 \pm 0.24$ \\
\hline $\mathrm{BD}-3$ & $1245 \pm 23$ & $25.45 \pm 1.26$ & $1.08 \pm 0.03$ & $0.90 \pm 0.03$ & $9.39 \pm 0.21$ \\
\hline BD-4 & $1224 \pm 35$ & $23.20 \pm 1.35$ & $1.05 \pm 0.02$ & $0.89 \pm 0.06$ & $8.93 \pm 0.34$ \\
\hline BD-5 & $1318 \pm 27$ & $27.21 \pm 1.30$ & $1.12 \pm 0.06$ & $0.83 \pm 0.05$ & $8.76 \pm 0.30$ \\
\hline BD-6 & $1336 \pm 32$ & $26.48 \pm 1.44$ & $1.04 \pm 0.08$ & $0.83 \pm 0.05$ & $8.69 \pm 0.37$ \\
\hline BD-8 & $1380 \pm 21$ & $26.65 \pm 1.88$ & $1.09 \pm 0.05$ & $0.90 \pm 0.03$ & $9.39 \pm 0.36$ \\
\hline BD-9 & $1262 \pm 73$ & $26.83 \pm 1.28$ & $1.08 \pm 0.06$ & $0.89 \pm 0.04$ & $8.93 \pm 0.29$ \\
\hline BD-10 & $1294 \pm 42$ & $26.25 \pm 1.36$ & $1.16 \pm 0.04$ & $0.83 \pm 0.05$ & $8.76 \pm 0.38$ \\
\hline
\end{tabular}

*Standard deviation $\mathrm{n}=3$

Table 4: Characteristics of immediate release atorvastatin calcium pellet formulations

\begin{tabular}{|c|c|c|c|c|c|}
\hline Formulation code & Average size* (mm) & Angle of repose $e^{* *} \theta^{\circ}$ & $\begin{array}{l}\text { Granule density }{ }^{* *} \\
\left(\mathrm{~g} / \mathrm{cm}^{3}\right)\end{array}$ & $\begin{array}{l}\text { Tapped density }{ }^{* *} \\
\left(\mathrm{~g} / \mathrm{cm}^{3}\right)\end{array}$ & $\begin{array}{l}\text { Carr's index }{ }^{* *} \\
(\%)\end{array}$ \\
\hline FR-1 & $1127 \pm 41$ & $25.14 \pm 1.52$ & $1.09 \pm 0.04$ & $0.79 \pm 0.05$ & $8.11 \pm 0.42$ \\
\hline FR2 & $1177 \pm 30$ & $26.42 \pm 1.24$ & $1.04 \pm 0.02$ & $0.81 \pm 0.04$ & $8.19 \pm 0.49$ \\
\hline FR-3 & $1255 \pm 43$ & $25.25 \pm 1.46$ & $1.07 \pm 0.08$ & $0.80 \pm 0.05$ & $9.21 \pm 0.44$ \\
\hline FR-4 & $1274 \pm 45$ & $24.19 \pm 1.33$ & $1.03 \pm 0.06$ & $0.75 \pm 0.05$ & $8.01 \pm 0.18$ \\
\hline FR-5 & $1371 \pm 50$ & $27.21 \pm 1.69$ & $1.05 \pm 0.04$ & $0.76 \pm 0.04$ & $8.24 \pm 0.80$ \\
\hline FR-6 & $1204 \pm 57$ & $26.18 \pm 1.27$ & $1.05 \pm 0.06$ & $0.83 \pm 0.03$ & $9.09 \pm 0.41$ \\
\hline FR-8 & $1208 \pm 32$ & $26.65 \pm 1.47$ & $1.06 \pm 0.05$ & $0.84 \pm 0.02$ & $8.54 \pm 0.54$ \\
\hline FR-9 & $1219 \pm 44$ & $26.55 \pm 1.24$ & $1.02 \pm 0.04$ & $0.81 \pm 0.04$ & $8.05 \pm 0.87$ \\
\hline FR-10 & $1244 \pm 37$ & $26.04 \pm 1.35$ & $1.07 \pm 0.06$ & $0.85 \pm 0.05$ & $8.46 \pm 1.03$ \\
\hline
\end{tabular}

*Standard deviation $\mathrm{n}=3$ 


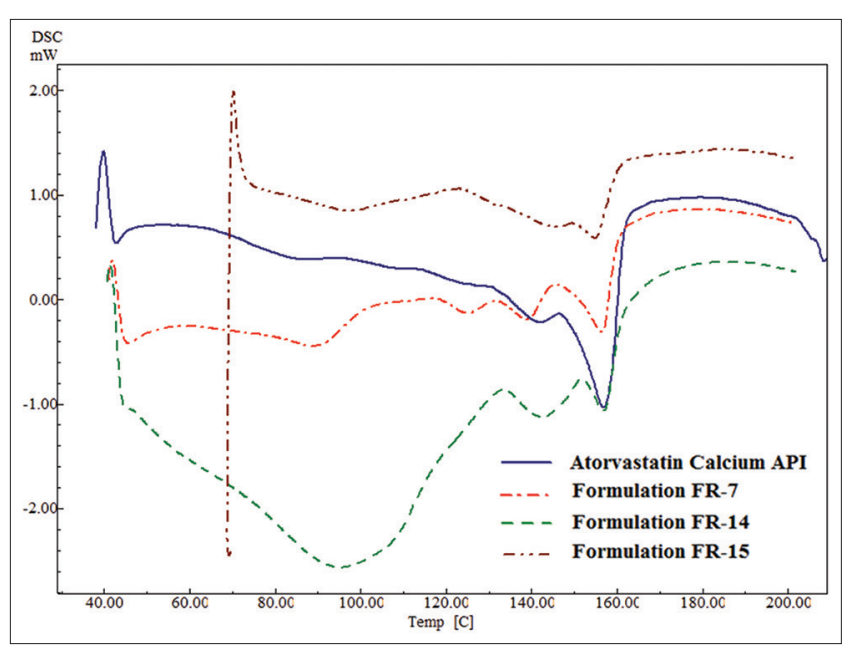

Fig. 4: Differential scanning calorimetry thermogram of atorvastatin calcium API, formulation FR-7, FR-14, and FR-15
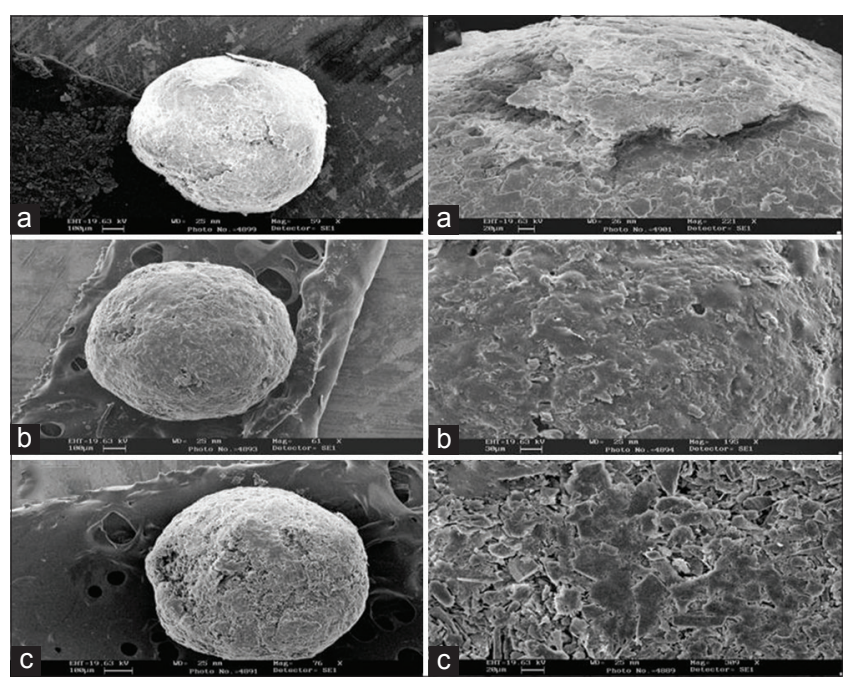

Fig. 5: Scanning electron microscopic of sustained release glibenclamide pellets: (a) formulation BD-2, (b) formulation BD-8, and (c) formulation BD-13 at different magnifications

$74.8 \pm 1.21-82.4 \pm 1.49 \%$ in successive unit operations when $100 \mathrm{~g}$ of bulk material is being used.

\section{Drug loading and encapsulation efficiency glibenclamide}

Percentage of drug loaded and percentage of drug encapsulated were found to be within the ranges of $2.28 \pm 0.23-2.55 \pm 0.15 \%$ and $85.40 \pm 1.21$ $95.51 \pm 1.23 \%$. Results suggested that as the concentration of polymer increased there was an increase in drug loading and encapsulation efficiency. Thus, from the results, it can be inferred that glibenclamide was distributed uniformly in the pellets with acceptable deviations.

Drug loading and encapsulation efficiency of atorvastatin calcium pellets

Percentage of drug loaded and percentage of drug encapsulated were found to be within the ranges of $3.06 \pm 0.18-3.80 \pm 0.31 \%$ and $87.15 \pm 0.96-95.19 \pm 1.76 \%$. Thus, from the results, it can be inferred that atorvastatin calcium was distributed uniformly in the pellets with acceptable deviations.

\section{Pellets disintegration time atorvastatin calcium}

Atorvastatin calcium pellets formulated using sodium starch glycolate as superdisintegrant had shown high disintegration when compared

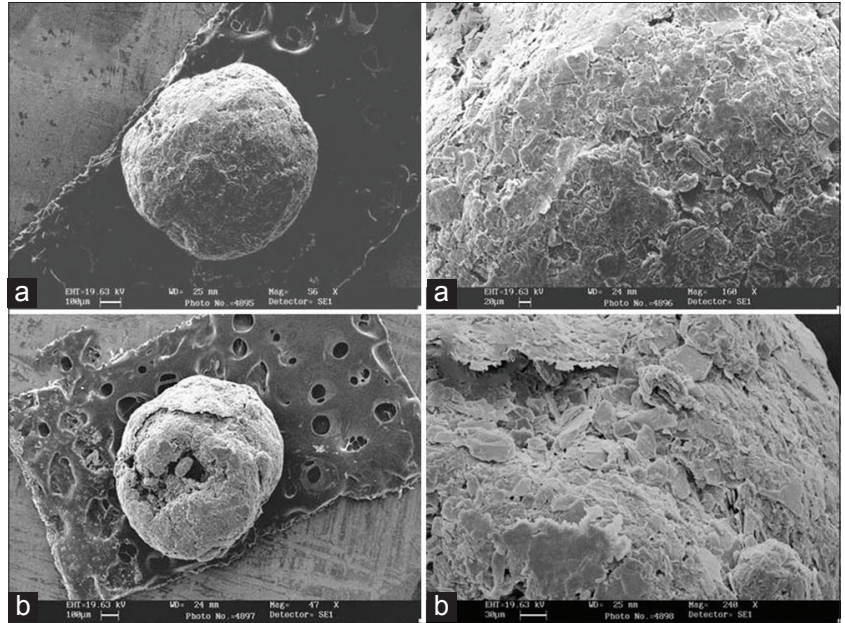

Fig. 6: Scanning electron microscopic of immediate release atorvastatin calcium pellets: (a) formulation FR-7 and

(b) formulation FR-14 at different magnifications

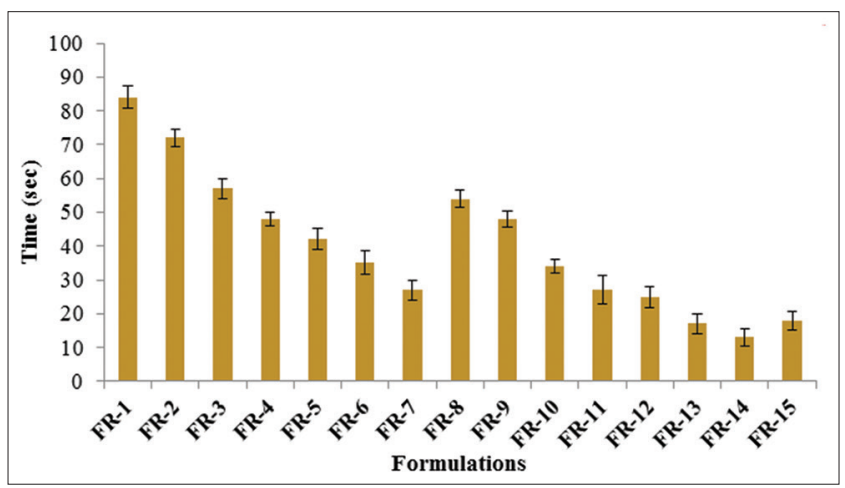

Fig. 7: Disintegration time of different formulations of immediate release atorvastatin calcium pellets

to croscarmellose sodium. As depicted in Fig. 7, results suggested that higher disintegration time is due to swelling of pellets when it comes to contact with aqueous medium and forming a gel, forming pores in the pellets prolonging the disintegration. While pellets formulated by using croscarmellose had shown enhanced disintegration by rapid swelling caused by capillary action.

\section{In vitro dissolution studies}

The sustained release glibenclamide and immediate release atorvastatin calcium pellets were mixed together in fixed-dose combination (FDC) and filled in a single hard gelatin capsule and evaluated for in vitro drug release study. As depicted in Figs. 8a-c and 9a and b, results suggested that as the concentration of polymer increases in glibenclamide pellets leaded to a significant decrease in dissolution of drug up to $12 \mathrm{~h}$. While for atorvastatin calcium pellets, containing superdisintegrant had shown the complete release of drug within $45 \mathrm{~min}$.

\section{CONCLUSION}

There is a strong prophylactic and clinical need to develop novel fixed combination delivery systems for the patients suffering from dyslipidemia in type-II diabetes mellitus for improvement of glucose tolerance with desired characteristics such as better therapeutic efficacy, convenience, reduced pill burden, and simplified administration of regimens with cost-effective medication. The developed FDC dosage forms, namely MUPSs, have demonstrated their superiority in both retarding the drug release of glibenclamide and immediate release of atorvastatin calcium. Thus, the study demonstrates that the developed FDC systems have a great appeal for the convenient treatment of 


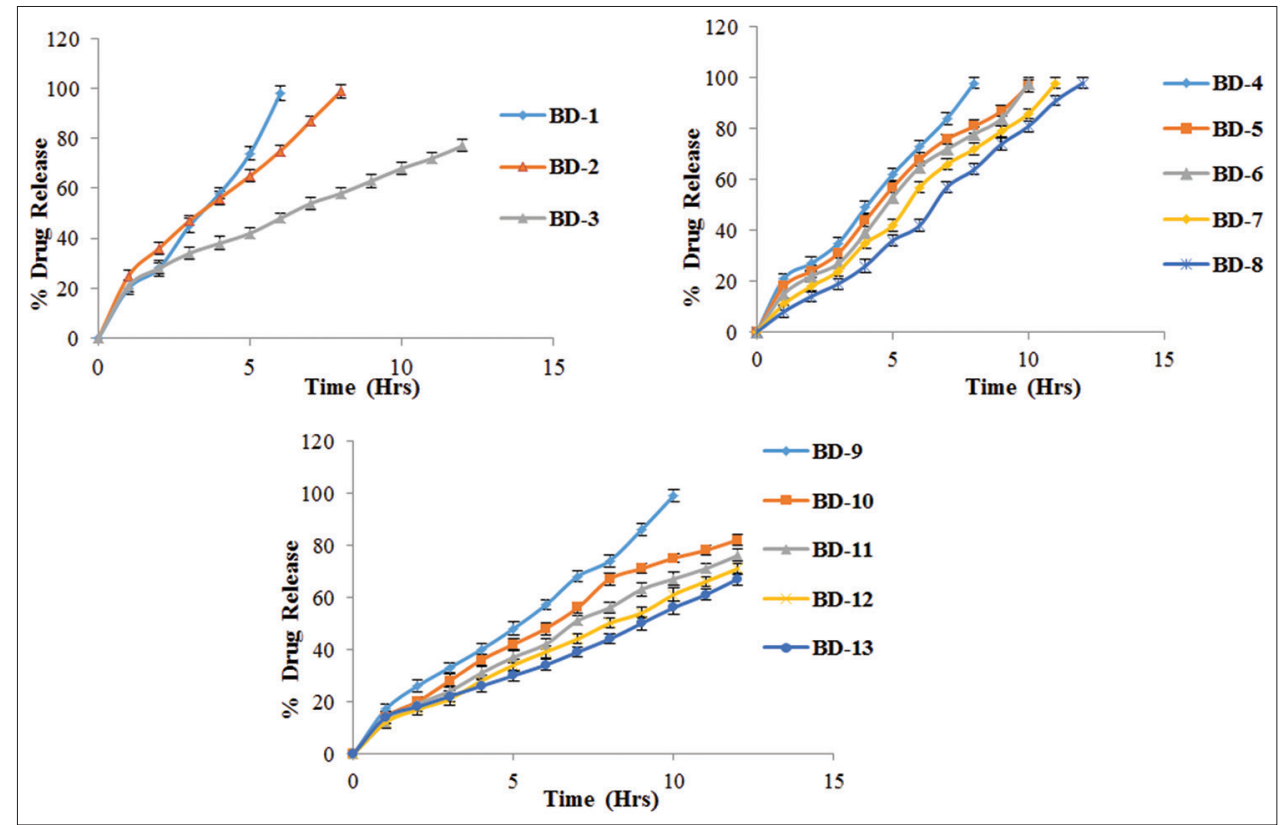

Fig. 8: (a-c) In-vitro dissolution profile of sustained release glibenclamide pellets (BD1-BD13)

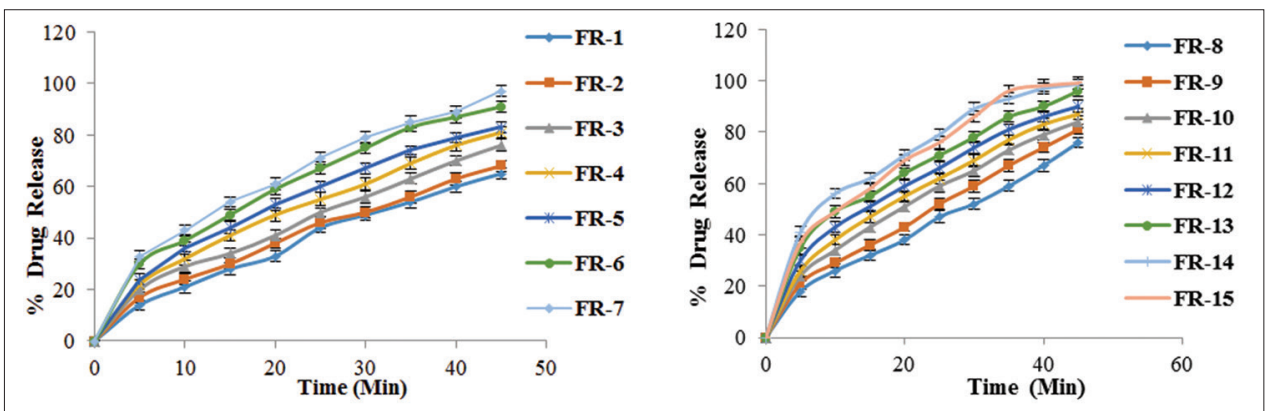

Fig. 9: (a and b) In vitro dissolution profile of atorvastatin calcium pellets (FR1-FR13)

diabetic dyslipidemia that may be explored in improving the limitations of existing monotherapy drug delivery systems.

\section{ACKNOWLEDGMENTS}

The authors express their gratitude to the JSS Academy of Higher Education and Research and JSS College of Pharmacy, Mysuru, for providing necessary support in due course of the work.

\section{AUTHORS' CONTRIBUTIONS}

The authors are a faculty in division of pharmaceutics and the work contributed on faculty development programme in the institution.

\section{CONFLICTS OF INTEREST}

The author confirms that this article content has no conflicts of interest.

\section{REFERENCES}

1. Almamory IA, Tsahel H. Detection level of urea, sugar, creatinine and hematology in patients of diabetic mellitus Type II. J Med Sci 2014;5:154-6.

2. American Diabetes Association. Report of the expert committee on the diagnosis and classification of diabetes mellitus. Diabetes Care 1997;20:1183-97.

3. Stamler J, Vaccaro O, Neaton JD, Wentworth D. Diabetes, other risk factors, and 12-yr cardiovascular mortality for men screened in the multiple risk factor intervention trial. Diabetes Care 1993;16:434-44.

4. McCarron P, Greenwood R, Elwood P, Shlomo YB, Bayer A, Baker I, et al. The incidence and aetiology of stroke in the caerphilly and speedwell collaborative Studies II: Risk factors of ischaemic stroke. Public Health 2001;115:12-20.

5. Deshpande RD, Gowda DV, Mahammad N. Design of Pistacia lentiscus (mastic gum) controlled release spheroids and investigating the influence of roll compaction. Ind Crops Prod 2013;44:603-10.

6. Papich MG. Saunders Handbook of Veterinary Drugs-E-Book: Small and Large Animal. St. Louis, Missouri, USA: Elsevier Health Sciences; 2015.

7. Kaplani AP, Malamataris S. Preparation and characterization of a new insoluble polymorphic form of glibenclamide. Int J Pharm 2000;195:239-46.

8. Ho JE, Paultre F, Mosca L. Is diabetes mellitus a cardiovascular disease risk equivalent for fatal stroke in women? Data from the women's pooling project. Stroke 2003;34:2812-6.

9. Patel SA, Patel NG, Joshi AB. Multiple unit pellet system (MUPS) based fast disintegrating delayed-release tablets for pantoprazole delivery. Int J Pharm Pharm Sci 2018;10:77-84.

10. Higuchi T, Connors KA. Phase-solubility Techniques. Adv Anal Chem Instrum 1965; 4:117-212.

11. Clarke GM, Newton JM, Short MD. Comparative gastrointestinal transit of pellet system of varying density. Int J Pharm 1995;114:1-11.

12. Du Pasquier A, Disma F, Bowmer T, Gozdz AS, Amatucci G, Tarascon JM. Differential scanning calorimetry studies of lithium ion and the reactivity of carbon anodes in plastic lithium ion batteries. J Electrochem Soc 1998;145:472-7.

13. Rojas J, Correa D. Comparative evaluation of the release properties of verapamil HCL and carbamazepine from microcrystalline cellulose II pellets. Int J Pharm Pharm Sci 2017;9:182-6.

14. Dash SK, Khan AS, Das SR, Padhan A, Rout D, Behera BC. Formulation and in-vitro evaluation of sustained released glibenclamide microspheres. Int J Pharm Sci Res 2012;3:1433-43. 